\title{
Toric intraocular lens implantation in comparison to Femto-assisted astigmatic keratotomy to correct astigmatism during phacoemulsification cataract surgeries
} Ashraf S. Shaarawy, MD*, Ahmed A. Elmassry, MD*, Hazem M. Elhenawy, MD*, Amr M. Elbaz Ibrahim

${ }^{\mathrm{a} D e p a r t m e n t ~ o f ~ O p h t h a l m o l o g y, ~ F a c u l t y ~ o f ~}$ Medicine at Alexandria University, Egypt

Correspondence to Ahmed A. Elmassry, MD, $\mathrm{PhD}$ El nour eye center,El Horya road Moustafa Kamel, Alexandria

The Egyptian Journal of Cataract and Refractive Surgery 2020,

\begin{abstract}
Background: for the comparison of the visual outcome including visual acuity and target refraction, surgical operative difficulties, and the results of the toric intraocular lens (IOL) implantation versus Femto-assisted astigmatic keratotomy (AK) in the correction of astigmatism during phacoemulsification.

Subjects \& Methods: A randomized comparative interventional study was demonstrated on cases with cataract surgical operations who were engaged from Alex Eye Center outpatient clinic, From May 2017 to January 2019. Forty-four eyes were involved in the current work; all of them had visually significant cataracts and mild manifest astigmatism (1.25 to 3.00 diopters). Twenty-two eyes had treated by Femto-assisted AK with the usage of a planned depth, optical zone, and length of the keratotomy valuated with Bascom palmer nomogram and adapted by Donnenfield nomogram and followed by implanting of an intraocular lens. A further 22 eyes were treated by Clear corneal $2.4 \mathrm{~mm}$ phacoemulsification with toric IOL implantation. All cases were followed-up for 6-months. Results: UCVA has exhibited a better outcome with a statistically significant change in the toric IOL group (mean of 0.73) in comparison to the AK group (mean of 0.57) at the end of the follow-up period. Also, BSCVA gives a better outcome in the toric IOL group (mean of 0.9 ) in comparison to the AK group (mean of 0.8 ). The difference has a statistical significance. Vector analysis concluded that: no significant change was existing in targetinduced astigmatism (TIA) in the studied groups. The surgically induced astigmatism (SIA) was high in the toric group in comparison to the AK group with a mean of 1.23 in the AK group and 2.17 in the toric group and a P-value of 0.0001 . The difference vector (DV) mean was 1.16 in the AK group and 0.92 in the toric group, P-value of 0.05 (no statistical significance), and the correction index (CI) means in the AK group and the toric IOL group were $0.75 \pm 0.53,0.81 \pm 0.35$ respectively.

Conclusion: A comparison of astigmatic keratotomy and the toric IOLs in the treatment of corneal astigmatism during phacoemulsification showed evidence that both techniques are efficient, predictable, and safe in reducing corneal astigmatism with an observed superiority of the toric IOLs this superiority of the toric IOL was observed in the better UCVA, BCVA, less residual astigmatism, and better indices of vector analysis.
\end{abstract}

Keywords:

Egypt J Cataract Refract 2020

(C) 2020 The Egyptian Journal of Cataract and Refractive Surgery 1687-6997

\section{Introduction}

For patients, cataract surgery is a unique, once-in-alifetime opportunity to reduce their need for glasses along with removing the cataract. Astigmatic refractive error correction could be addressed to patients with significant cataract and corneal astigmatism with the surgery, and it is well accepted that more than $72 \%$ of people have $0.50 \mathrm{D}$ or more of astigmatism. [1]

Unfortunately, postoperative astigmatism is not an unusual event. Hoffer KJ et al is a large study of a cataract population reported that corneal astigmatism between $0.75 \mathrm{D}$ and $1.50 \mathrm{D}$ was present in more than $40 \%$ of patients, with higher levels in nearly $20 \%$. [2]

The goal of modern cataract surgery is not just to remove the cataractous lens, but also to provide the patient with good uncorrected vision. When evaluating patients for surgery, it is necessary to consider not only the spherical equivalent but also the expected residual astigmatism. [3]

Even if the spherical equivalent is exactly on target, the quality of vision is compromised by residual astigmatism. With approximately $86 \%$ of patients with cataracts needing some kind of astigmatic correction[4], it is not surprising that several different treatment options exist. [5]

Limbal relaxing incisions (LRI) are perhaps the most common technique to correct small amounts of performed for many years. Providing this treatment is relatively inexpensive, and the procedure is quite reliable for reducing astigmatism of $1.25 \mathrm{D}$ or less, which is sufficient for the majority of patients. [6]

\footnotetext{
This is an open access journal, and articles are distributed under the terms of the Creative Commons Attribution-NonCommercial-ShareAlike 4.0 License, which allows others to remix, tweak, and build upon the work non-commercially, as long as appropriate credit is given and the new creations are licensed under the identical terms.
} astigmatism at the time of cataract surgery; it has been 
LRIs are based on the same principle as all-incisional refractive surgery; that is, a partial-thickness corneal incision leads to flattening of the cornea. [7] Technically, LRI is a tissue addition procedure like other incisional refractive surgeries; as the gaped wound heals, it fills with scar tissue and results in a flattening of that meridian. [7]

By comparison, in astigmatic keratotomy, the incisions are placed within the central corneal zone, which leads to greater refractive impact per incision size, but also greater refractive instability. [8]

The strength of LRI is its simplicity and ease of use: It's a comparatively non-invasive procedure that can safely correct corneal astigmatism, and the flexibility of incision placement allows the correction of some amount of irregular astigmatism as well. [9]

However, LRIs with a diamond blade does have limitations. Since the incision is made manually, skip lesions can occur and there is always a potential for perforation. Also, there is more variability in results when attempting to treat higher levels of astigmatism. $[10,11]$

With femtosecond lasers becoming more common, femtosecond astigmatic keratotomy is a newly developing surgical procedure that has enormous potential. The ability to program the laser power, length of the incision arc, depth, and even optical zone makes the cuts highly precise and repeatable. There are no skip lesions and a minimized risk of perforation. [12, 13]

An alternate method to address preoperative corneal astigmatism is the implantation of toric IOLs. Toric IOL implantation allows management of corneal astigmatism, leading to spectacle independence for increasing numbers of cataract surgery patients. $[14,15]$

The ideal patients for toric IOL implantation are those with regular astigmatism; however, good outcomes have been reported in cases of mild to moderate irregular astigmatism with fairly symmetrical preoperative readings within the central $4 \mathrm{~mm}$ cornea. It is important to take into account the vector sum of the pre-existing corneal astigmatism and surgeon-induced astigmatism when determining the power and meridian of a toric IOL. [14, 15]

Another factor to consider is the impact of effective lens position and the sphero-equivalent power of the IOL on the effective toricity of the IOL at the corneal plane. The effective toricity diminishes with increasing anterior chamber depth and lower IOL spherical power. Some of the nomograms like the Holladay IOL Consultant Program (Holladay Consulting) take these factors into account when calculating toric IOL power. [16]

Correct intra-operative alignment of the IOL and good postoperative rotational stability are critical factors for achieving the desired astigmatic correction. When a toric IOL is misaligned, there is a reduction in the cylinder correction along the desired meridian and induction of the cylinder at a new meridian. Bench studies suggest a $33 \%$ loss of astigmatic correction if the optic rotates 10 degrees. [17]

Postoperatively, the orientation axis of the toric IOL can be verified to confirm that no IOL rotation has occurred. Toric IOL misalignment can be determined by using the slit lamp biomicroscope (with rotating slit and full mydriasis), the postoperative residual refraction and keratometry values, and wavefront aberrometry. [14-15]

Misalignment is determined by using postoperative manifest refraction, the amount of astigmatism at the corneal plane, and the IOL axis to determine the magnitude of misalignment, the direction of rotation needed, and residual astigmatism after IOL rotation. [19]

Realignment of a rotated toric IOL should be performed as soon as possible because adhesions form between the capsular bag and the IOL optic. Also, it is reasonable to allow enough time for refraction to stabilize but before fibrotic adhesion between the anterior and posterior capsules and IOL haptics. [20]

\section{Patients and methods}

A randomized comparative interventional investigation was demonstrated on cataractous cases employed from the Alex Eye Center out-patient clinic. From May 2017 to January 2019. 44 eyes were involved in the study. 22 eyes were treated by Femto-assisted AK using planned depth, optical zone, and length of the keratotomy estimated with Bascom palmer nomogram and adapted Donnenfield nomogram followed by the intraocular lens implantation and 22 eyes managed by Clear corneal $2.4 \mathrm{~mm}$ phacoemulsification with implantation of toric IOL. The Whole cases were followed up for 6 months.

Cases involved in the study had visually significant cataract and astigmatism ranging from 1.25 to 3.00 diopters

All patients with underlying ocular pathology were excluded from the study.

- A complete examination of (UCVA), (BCVA). Calculation of corneal clarity as well as the cataract grade according to the LOCS III system. IOP. Dilated fundus examination. If the media hinders proper visualization of the posterior segment due to dense cataracts, B-scan ultrasound was used for the detection of any posterior segment anomalies. Biometry using optical biometry (IOL Master, Carl Zeiss Meditec). The intraocular lens was selected following the estimates from biometry utilizing predominantly the SRK-T formula, but occasionally other third-generation formulae were employed when significant axial length variation occurred. A scan was employed to calculate the axial length in cases 
with dense cataracts and the measurements are introduced in the (IOL Master, Carl Zeiss Meditec) to obtain the IOL calculation.

1. In group 1 corneal astigmatisms were obtained from the (IOL Master, Carl Zeiss Meditec, and the length, depth, and site of the astigmatic keratotomies were designed according to Bascom Palmer nomogram for femtosecond laser- supported astigmatic keratotomy that is in turn modified from Lindstrom nomogram and adopted by Donnenfield nomogram. [21]

2. In group 2, enVista ${ }^{\circledR}$ Toric Intraocular Lens biometry and design were performed using the specific online IOL calculator for Bausch + Lomb (envista. Toric calculator. com)

A Written Clear agreement was got from all cases following the Declaration of Helsinki with a clarification of advantages and possible risks and complications. Ethics approval was obtained from the faculty of medicine, University of Alexandria Human Research Ethics Committee for the assessment of the safety and refractive results of the two operative procedures.

\section{Preoperative preparation:}

The marking of all patients was performed just preoperative in an upright position on a slit lamp in the vertical and horizontal axis. Marking will be doublechecked in an upright position using a portable electronic marker (ASICO AXsys one-step electronic marker).

\section{In group 1, Femto assisted cataract with astigmatic keratotomy}

The femtosecond laser system, Victus ${ }^{\circledR}$ by Bausch and Lomb (Rochester, New York, USA) was used in the femtosecond laser studied group. The software version was updated at the time of the study.

\section{Surgical Steps of FLACS:}

Corneal incisions: the principal wound and two sideport were created then capsulotomy and Lens fragmentation with grid patterns.

-In single arcuate astigmatic keratotomy. A single arcuate keratotomy cut was paired on the contrary meridian with the principal corneal cut for phacoemulsification.

-In double arcuate astigmatic keratotomy double arcuate keratotomy incisions were located on the steep axis

-The design of the AK was set according to the Bascom Palmer nomogram for femtosecond laser-assisted astigmatic keratotomy that is turn modified from Lindstrom nomogram and modified donnenfield nomogram [21]

-The deepness of astigmatic keratotomy was adjusted at 80-90 percent of the depth (according to the nomogram) which is measured intra-operative after docking to perform corneal incision guided with the live OCT included in the victus platform, the side-cut angled at 90-degrees. The optical region diameter was adjusted at $8-9 \mathrm{~mm}$. The extent of the angular arc length of the keratotomy incision was ranging from $45^{\circ}$ to $90^{\circ}$.

-Parameters of the AK were used as high energy and slight spot spacing as possible to keep the AK wound opened without tissue bridges to make it close as possible to the nomogram.

\section{In group 2, enVista ${ }^{\circledR}$ Toric Intraocular Lens}

Corneal incisions were made utilizing a $2.4 \mathrm{~mm}$ keratome for principle incision located in all patients on the planned axis calculated by the online calculator (envista.toriccalculator.com) and a $1.2 \mathrm{~mm}$ blade for the side ports. The front chamber was full of viscoelastic. In group-1, the continuous curvilinear capsulorhexis (CCC) was made by capsulorhexis forceps. Lens segmentation was done via a divide-andconquer method.

\section{Vector analysis for astigmatism}

Pre-operative and 6-months post-operative records for keratometric astigmatism were evaluated by the Alpins technique [22] in addition to the SIA calculator program version2.1 [23] in which the preoperative and postoperative K-readings and their axes were utilized to assess the actual variation in astigmatism record with attention to the modification in the astigmatic axis. Three essential factors of the vector analysis: Target-induced astigmatism (TIA), which is astigmatic alter (magnitude and axis) the operation is planned to encourage. The surgically-induced-astigmatism (SIA) was the amount and axis of astigmatism the operation has previously encouraged. The difference-vector (DV) was represented as the vector that permits the attained astigmatic result to reach the goal of astigmatism. This is an absolute count of achievement and is preferably zero. The correction-index (CI) was estimated as the ratio of the value of SIA to the value of TIA. The CI is preferably 1.0. It is greater than 1.0 if an overcorrection happened and less than 1.0 if an undercorrection happened. Coefficient of adjustment (CA is the inverse of the CI, the CA counts the alteration wanted for the primary operative plan to achieve a CI of 1 . The CA could be utilized to improve nomograms for upcoming operations. The index of success was estimated by dividing the value of DV by the value of TIA. This is a relative count of success and is preferably zero. The total mean value of residual astigmatism and residual astigmatism at the meridian of intervention were estimated. The power vector components of Jackson cross-cylinder with the axis at $\mathrm{J} 45\left(\right.$ or $\left.135^{\circ}\right)$ and $\mathrm{J} 0\left(\right.$ or $\left.180^{\circ}\right)$ were also evaluated per the next equations: $\mathrm{J} 0=-(\mathrm{C} / 2) \times \mathrm{Cos}(2 \alpha)$ and $\mathrm{J} 45=$ $-(\mathrm{C} / 2) \times \operatorname{Sin}(2 \alpha)$, where J0 is the Jackson crosscylinder power at axis $90^{\circ}$ and $180^{\circ}, \mathrm{J} 45$ is the Jackson cross-cylinder power at axis $45^{\circ}$ and $135^{\circ}, \mathrm{C}$ is the negative cylinder, and $\alpha$ is the steep axis. [24] 


\section{Results}

Patients' age had a mean of $68.31 \pm 8.73$ and $65.88 \pm 10.02$ in AK and Toric IOL groups respectively. AK group had 12 right eyes and 10 left eyes with 9 males and 13 females). Toric IOL group had 9 eyes on the right side and 13 on the left side with 14 eyes of males and 8 females. This age and sex difference was not statistically significant.

UCVA pre-operative was statistically of no difference in the studied groups also no statistical change was existing among the two groups on the first day postoperative, but the UCVA was improved in the toric IOL group (group-2) and that shown to be of a statistical difference in the $3^{\text {rd }}$ month and the $6^{\text {th }}$ month postoperative. In the AK group (group-1) UCVA was of mean 0.09 pre-operative then become 0.51 on the $1^{\text {st }}$ day follow up, 0.57 after 3 months, and 0.57 in the $6^{\text {th }}$ month. In group-2 UCVA was of mean 0.08 preoperative then become 0.61 on the $1^{\text {st }}$ day follow up, 0.69 after 3 months, and 0.73 in the $6^{\text {th }}$ month.

BCVA pre-operative was statistically of no difference in the studied groups also no statistical change was found among the studied groups on the first day postoperative, but the BCVA was better in group-2 and that shown to be of a statistical difference in the $3^{\text {rd }}$ month and the $6^{\text {th }}$ month. In the group-1 BCVA was of mean 0.08 pre-operative then become 0.77 on the $1^{\text {st }}$-day follow-up, 0.79 after 3 months, and 0.8 in the $6^{\text {th }}$ month. In group 2 BCVA was of mean 0.09 pre-operative then become 0.8 on the $1^{\text {st }}$-day follow-up, 0.89 after 3 months, and 0.9 in the $6^{\text {th }}$ months.

Table (1): Percentages of cases accomplishing refractive Astigmatism amounts at end of follow up in the two studied groups.

$X^{2}=$ Chi square test.$P$ is significant if $\leq 0.05 *$ Significant difference

Figure 3
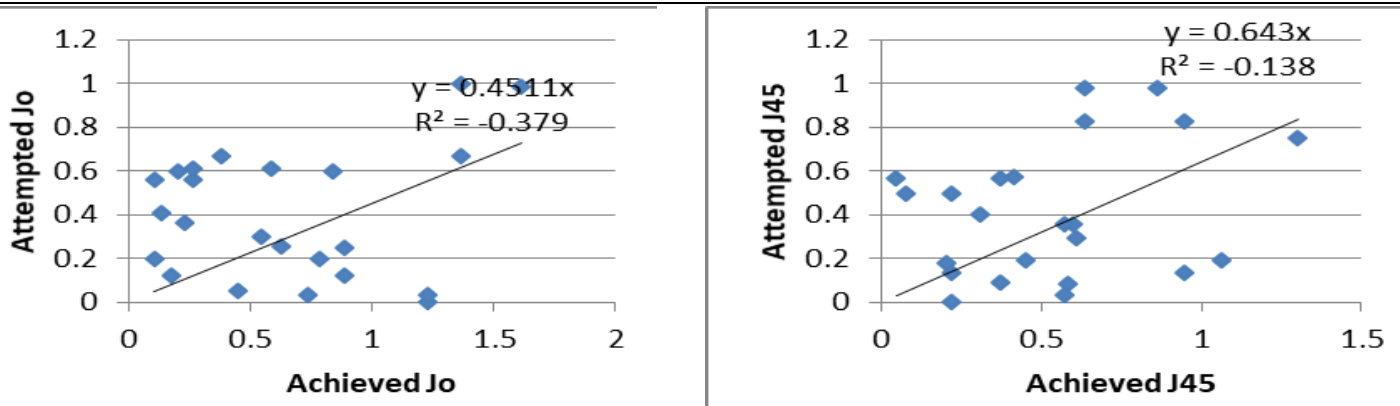


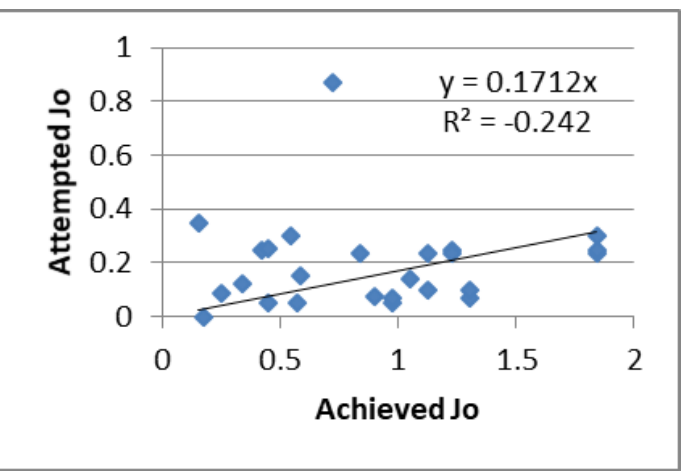

Attempted versus achieved $\mathrm{J}_{0}, \mathrm{~J}_{45}$ in group 2

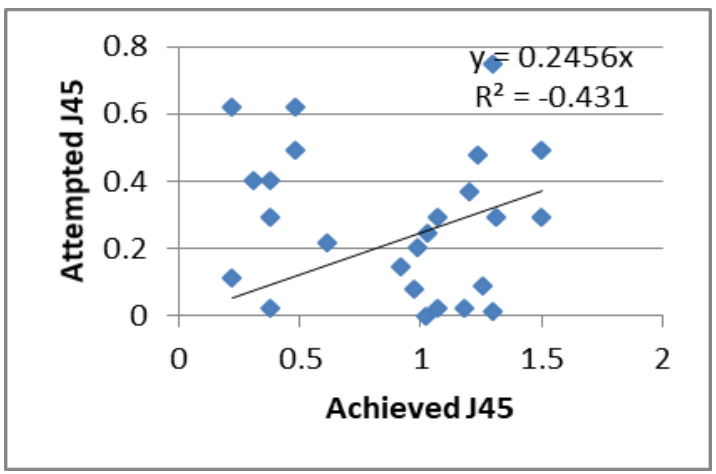

Figure (3.4) Indicates the tried against the accomplished astigmatic components $\mathrm{J} 0$ and $\mathrm{J} 45$ of the power vector analysis in group-1 and group2. Group-2 had a greater correlation among the tried and accomplished parameters

Table (2) illustrates the vector analysis parameters TIA, SIA, DV, and CI. TIA means in group-1 is 1.84 and 2.61 in group- 2 with a P-value of 0.001 and no significant difference. The SIA mean is 1.23 in group-1 and 2.17 in group-2, the higher number of group-2 is of significant difference with a P-value of 0.0001 . The DV mean is 1.16 in group- 1 and 0.92 in group-2, the higher number of group-1 is not statistically significant with a P-value of 0.05 . The CI mean is 0.75 in group- 1 and 0.81 in group- 2 , the higher number of group-2 is not a statistically significant difference with a P-value of 0.322 . The angle of error is positive in both groups denoting that the achieved correction is counterclockwise to the intended axis.

Table (2): Comparison between the two studied groups regarding TIA, SIA, DV, and CI.

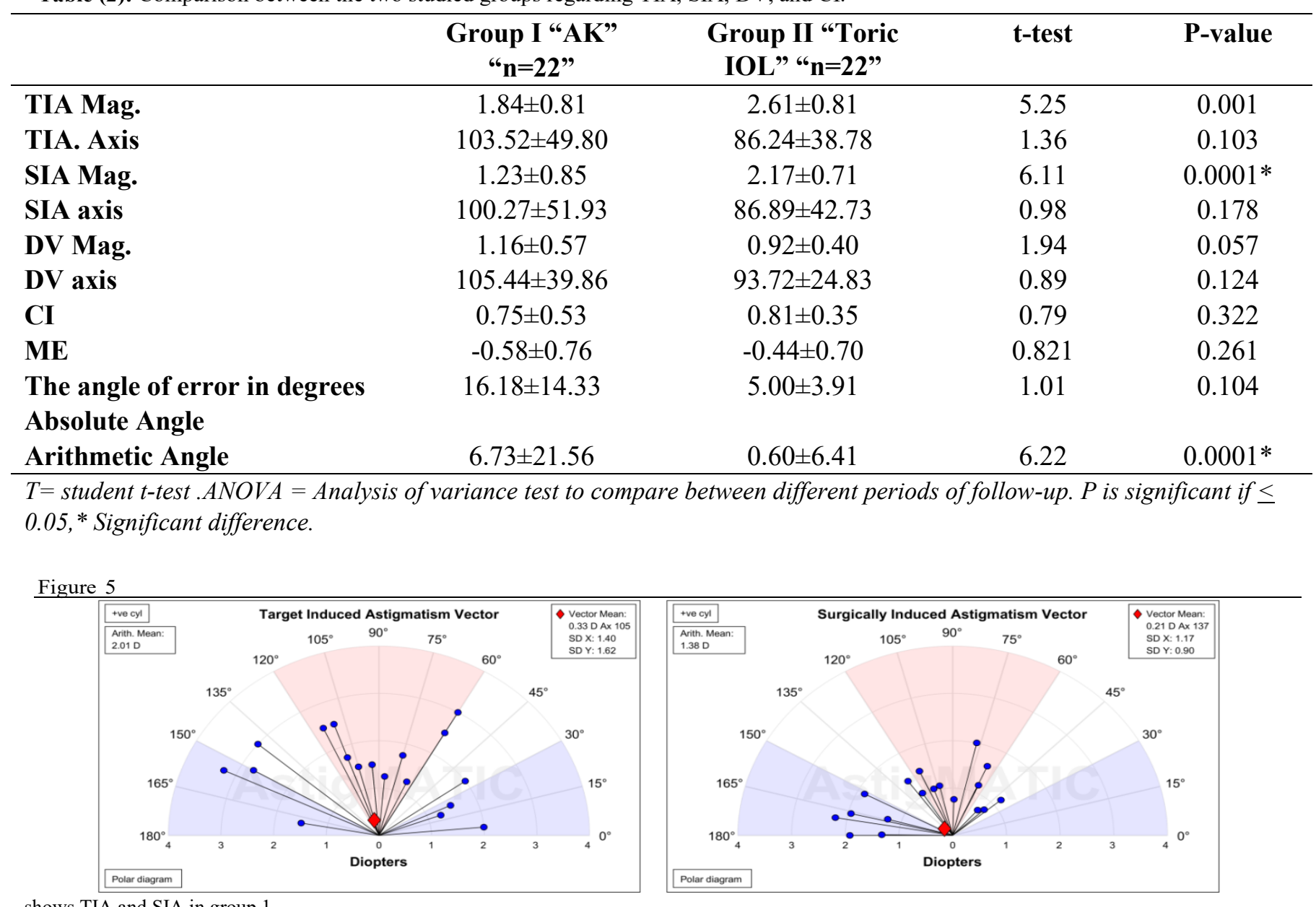


Figure 6
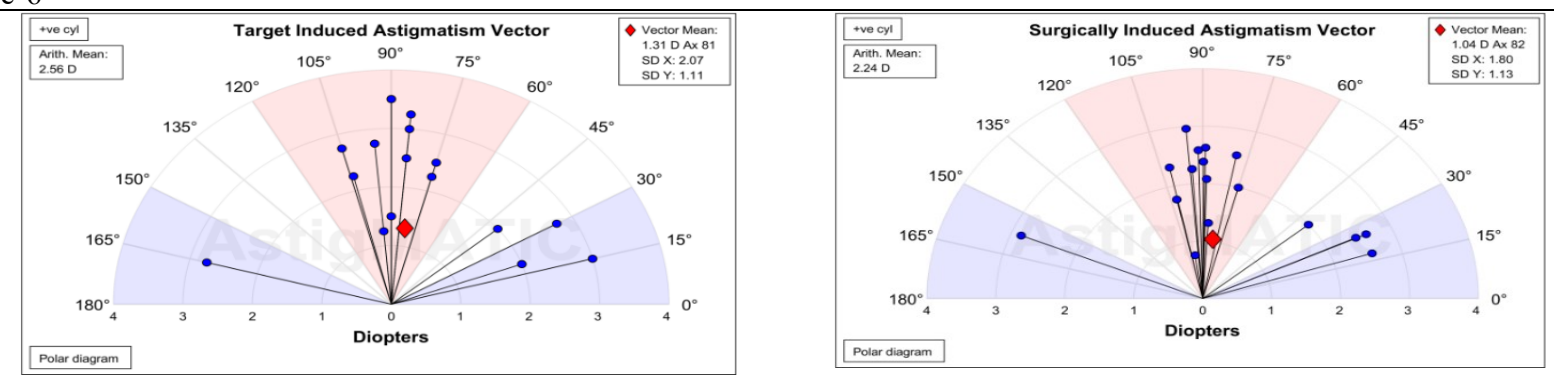

shows TIA and SIA in group 2

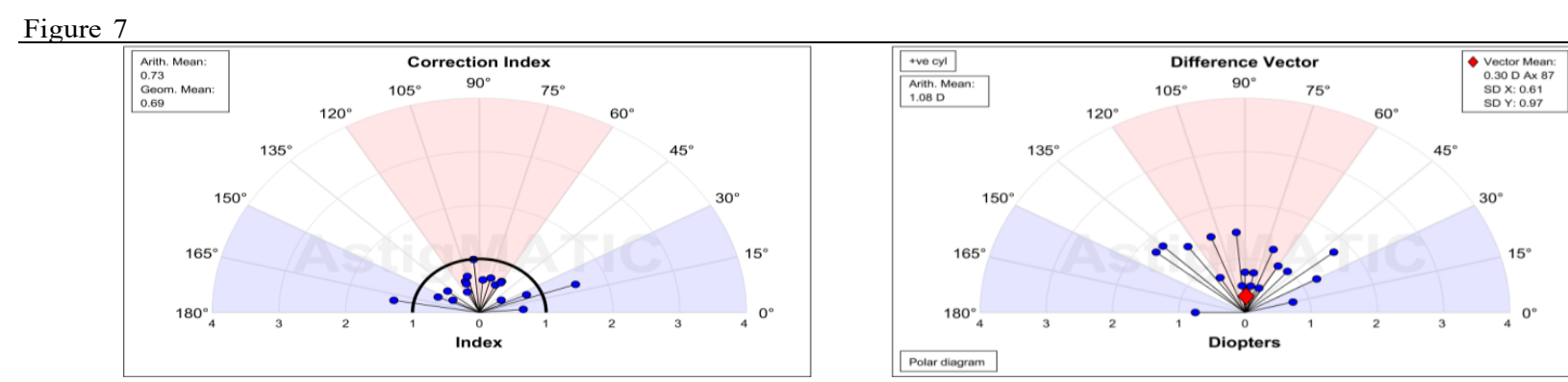

shows CI and DV in group 1

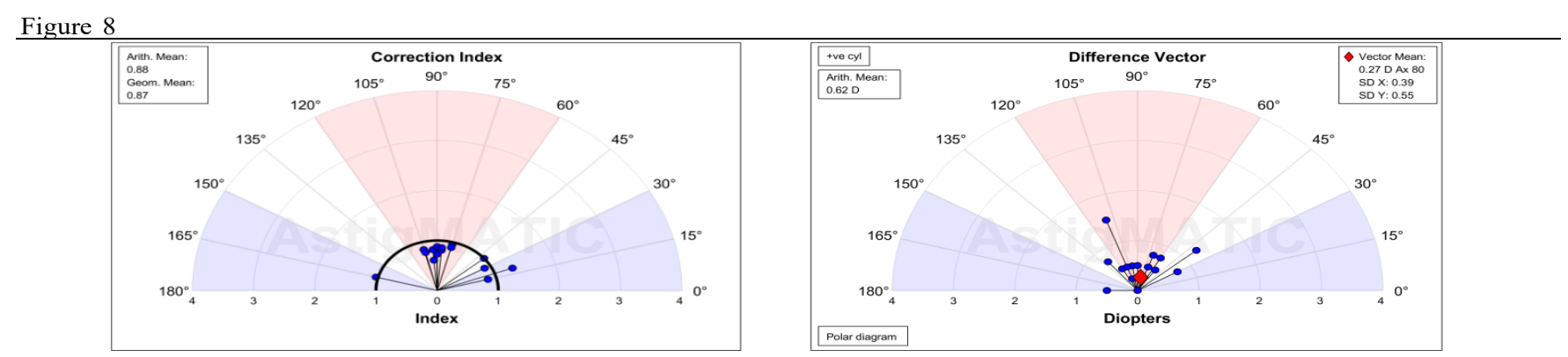

shows CI and DV in group 2

\section{Discussion}

Modern cataract surgical operations aim to reach the finest vision quality and maximum spectacle independence. Uncorrected astigmatism stays the main optical aberration afterward myopia and hypermetropia producing a decreased uncorrected vision afterward cataract operation.

Corneal relaxing incisions were utilized in combination with non-toric IOLs to decrease or remove astigmatism; however, these methods were restricted by induced high order aberrations, the degree of astigmatism that could be operated, and the long-term mechanical stability of the cornea after relaxing cuts. [27]

Arcuate keratotomy is a well-known technique for the treatment of astigmatism, and femtosecond laser technology delivers a modern operative modality. Femtosecond laserassisted arcuate keratotomy [FS-AK) was lately stated as a successful choice for decreasing the naturally happening astigmatism and high astigmatism afterward keratoplasty. [28,29]

This study had a minimum follow-up interval of 6-months to record the possible dynamic corneal variations in the incisional group. Utilizing the Lindstrom nomogram and the improved Donnenfeld nomogram [21] either single or paired arcuate relaxing incisions.

Toric IOLs were initiated in 1994; though, initial outcomes were un-predictable owing to the rotational instability, with about 20 percent of IOLs rotating greater than $30^{\circ}$. [30] The introduction of toric IOLs with suitable rotational constancy makes them a feasible option for several doctors as the necessity for further costly instrumentations or special operative skills is removed.

The enVista toric (Model MX-60T) is a foldable, singlepiece, $6.0-\mathrm{mm}$ aspheric optic IOL, intended for implantation in the capsular. It is obtainable in powers from 1.25 to 5.75 $\mathrm{D}$; at the period of the work, the existing powers ranging from $+6.0 \mathrm{D}$ to +30 D. [31]

22 eyes are treated with Femto-assisted AK utilizing (VICTUS femtosecond laser platform Bausch + Lomb's ), planned with Bascom palmer_nomogram and improved Donnenfield nomogram with implanting of (Akreos Adapt AO lens Bausch + Lomb's ) and 22 eyes treated by Clear corneal $2.4 \mathrm{~mm}$ phacoemulsification with toric IOL implanting (enVista ${ }^{\circledR}$ Toric Intraocular Lens). [32]

The UCVA and BCVA results in this study preoperative and on the first day postoperative were shown to be of no significant difference and on follow up in the third month. UCVA is revealed to be improved with a statistical change in the toric IOL group with a mean of 0.73 and a mean of 0.57 in the AK group at the end of the follow-up. BCVA as well is shown to be better in the toric OL group with a mean of 0.9 and 0.8 in the AK group. The change was statistically significant. 
Mingo-Botı'n et al,[33] made a comparable investigation but with marginal instead of corneal relaxing cuts. They recorded that 3 months post-operatively, UDVA with a toric IOL was $20 / 40$ or larger in $95 \%$ of eyes and $20 / 30$ or larger in $75 \%$ of eyes; mean residual refractive astigmatism was $0.61+0.41 \mathrm{D}$ with a toric IOL and $1.32+\ldots 0.60 \mathrm{D}$ with relaxing cuts.

Visser et al ${ }^{[34]}$ investigated the toric IOL 67 eyes with previous corneal astigmatism of at least $2.25 \mathrm{D}$; the mean postoperative UDVA was $0.61+\ldots 0.26$, with $83 \%$ of eyes having a UDVA of 20/40 or higher and a mean residual refractive cylinder of $0.75+0.49$ D. Carey et al ${ }^{[35]}$ investigated the toric IOL in eyes with preexisting corneal astigmatism of at least $1.5 \mathrm{D}$ and reported that $88 \%$ of eyes had UDVA of $20 / 40$ or higher with a $65 \%$ mean decrease in astigmatism.

Theresa Ruckl et al [36] operated on 16 eyes with Femtoassisted intrastromal $\mathrm{AK}$ and after 6-month corneal astigmatism reduced from $2.68 \mathrm{D}$ to $0.58 \mathrm{D}$ afterward 6months next intrastromal arcuate keratotomy. The mean UDVA enhanced significantly from pre-operatively to six months next intrastromal arcuate keratotomy (P0.009). 5eyes $(31.3 \%)$ had unaffected UDVA, and 11-eyes (68.8\%) had a mean improvement of $2.8 \pm 1.47$ lines

Timothy V. Roberts et al [37] compared the astigmatic keratotomy and the toric IOL to correct astigmatism during phacoemulsification respectively; $44.4 \%$ and $82.2 \%$ of eyes were $1.00 \mathrm{D}$ or less $(\mathrm{P}=0.000)$, and $16.7 \%, 35.7 \%$, and of eyes were $0.50 \mathrm{D}$ or less $(\mathrm{P}=0.000)$, respectively. As aforementioned in the table (1) in this study $90.9 \%$ of the toric group $72.7 \%$ of the AK group were within $1 \mathrm{D}(\mathrm{P}$ $=0.013 *)$ and $77.3 \%$ of the toric group $63.6 \%$ of the AK group were within $0.5 \mathrm{D}$ and less $\left(\mathrm{P}=0.0 .043^{*}\right)$

For the vector analysis, the refractive and corneal astigmatism were transformed from the sphero-cylinder representation to power vector notation with the application of Fourier transformation. The power vector components of Jackson cross-cylinder with the axis at $\mathrm{J}_{45}$ (or $135^{\circ}$ ) and $\mathrm{J}_{0}\left(\right.$ or $\left.180^{\circ}\right)$ were also estimated in accordance to the next functions: $\mathrm{J}_{0}=-(\mathrm{C} / 2) \times \operatorname{Cos}(2 \alpha)$ and $\mathrm{J}_{45}=-(\mathrm{C} / 2) \times \operatorname{Sin}$ $(2 \alpha)$, whereas $J_{0}$ is the Jackson cross-cylinder power at axis $90^{\circ}$ and $180^{\circ}, \mathrm{J}_{45}$ is the Jackson cross-cylinder power at axis $45^{\circ}$ and $135^{\circ}, \mathrm{C}$ is the negative cylinder, and $\alpha$ is the steep axis. [38]

In this study, $\mathrm{J}_{0}$ pre-operative mean was -0.45 in the $\mathrm{AK}$ group and -0.08 in the toric IOL group. THE post-operative $\mathrm{J}_{0}$ mean was 0.39 in the AK group and -0.04 in the toric IOL group. $\mathrm{J}_{45}$ pre-operative mean was -0.06 in group 1 and -0.31 in group 2. Post-operative $\mathrm{J}_{45}$ mean was -0.15 in group 1 and -0.06 in group 2 . Figure $(1 \& 2)$ illustrates the scatterplot of the astigmatic component of the refractive power vector $\left(\mathrm{J}_{0}\right.$, $\mathrm{J}_{45}$ ) per- and post-operatively. The studied groups exhibited a raised data-points concentration near the origin showing a total improvement after the operation. Anecdotally, the datapoints concentration was denser in the toric IOL group. The results were the same as of Timothy V. Roberts et al [39] that compared the $(\mathrm{J} 0, \mathrm{~J} 45)$ pre and post-operative in the patients operated with astigmatic keratotomy and others with toric IOL implantation and the scatter-plot of the astigmatic component of the refractive power vector ( $\mathrm{J} 0, \mathrm{~J} 45)$ displayed a raised data-points concentration near the origin showing a total improving after the operation.
In this study, the attempted versus achieved astigmatic components $\mathrm{J}_{0}$ and $\mathrm{J}_{45}$ of the power vector analysis in the $\mathrm{AK}$ group (group1) and in the AK group (group2) were shown in Figures $(3 \& 4)$. The toric IOL group has a higher correlation among the tried and accomplished parameters. The results have an agreement with the data of Theresa Ruckl et al [36] In this study, the vector analysis parameters TIA, SIA, DV, and correction index are shown in table (2) no significant change in the TIA in the studied groups. The results of SIA were higher in the toric group in comparison to the AK group with a mean of 1.23 in the AK group and 2.17 in the toric group and a P-value of 0.0001 the results were shown to be of statistical difference. The DV mean is 1.16 in the AK group and 0.92 in the toric group, the high number of group-1 is not statistically significant with a P-value of 0.05 . The angle of error is positive in the studied groups denoting that the reached correction is counter-clockwise to the intended axis and the ME mean error value means in the $\mathrm{AK}$ group was -0.58 and in the toric IOL group was -0.44 denoting slight under correction in both groups.

The basic concept of all the astigmatic keratotomy nomograms depends on the coupling effect of the cuts placed on the steep axis and induces flatting at the same axis and steepening on the counter axis. Rise the influence of the astigmatic keratotomy by increasing the depth, length, and approaching more to the optical center. The AK cuts can be as near to $4 \mathrm{~mm}$ to the center or very peripheral at $11 \mathrm{~mm}$ as limbal relaxing incision LRI.[40,41] a balance between the magnitudes of astigmatism could be corrected and the possible opposing influences induced by incisions located near the visual axis. Any corneal incision can induce higherorder aberrations. But any incision as well can induce higher-order aberrations.

Navarro R et al [42] investigated the corneal optical and biomechanical variations that the astigmatic keratotomy causes utilizing a limited ray-tracing calculation. That work reported a raise in optical aberrations caused by arcuate keratotomy. High-order deviations like astigmatism, coma, and trefoil are the highest frequently happened, ${ }^{[45]}$ but with peripheral incisions, the deviations are much fewer expected to influence the optical quality of the anterior corneal surface. $[43,44]$

The hazard of irregular astigmatism and vision fluctuations seems to rise with incisions closer to the visual axis, [47] with peripheral limbal incisions more possible to undercorrect ${ }^{[46]}$ the refractive advantage from collective astigmatic keratotomy and cataract surgical operation has to be maintained at 3 years. [47]

In this study diameter of the astigmatic keratotomy was chosen to be fixed at $8-9 \mathrm{~mm}$, to be balanced between the efficiency of the astigmatic keratotomy and not to implicate high order aberrations. The changes in the other parameters such as:

-The depth of the incision with the safety produced with Femto-machine life OCT (VICTUS femtosecond laser platform Bausch + Lomb's).

-The length of the incision following the architecture of the design concerning corneal incisions.

Those parameters consider it safer to be changed other than the diameter which may induce high order aberrations if approaching the center. 
Alignment and IOL steadiness are vital to the outcome of toric IOLs as misalignment outcomes in residual astigmatism, with about $10 \%$ of the cylindrical correcting lost for every $3^{\circ}$ of misalignment of the IOL. This could have resulted from 3-factors: imprecise marking of the corneal meridian pre-operatively, imprecise alignment of the IOL through operation, or postoperative rotation of the IOL. $[46,48,49]$

For the toric IOL group, no significant rotation was noticed. As shown in table (1) there were only two cases of residual astigmatism of more than 1 diopter. Also, the follow-ups along 6 months were shown to be more stable. The cases of the higher residual astigmatism were fully dilated with revision of the marking on the slit lamp and no significant rotation was exist in all the cases. There was no need for secondary surgical intervention. However, the technique we utilized to count IOL alignment isn't so perfect, it is a practical and effective technique for routine practice.

In a US FDA clinical trial, $92 \%$ of the cases who received the enVista IOL suffered from not greater than $5^{\circ}$ of rotation from the day of operation to six months after operation; the absolute mean rotation at six months was 3 degrees. [50]

Poll et al [51] that compared the astigmatic keratotomy mostly LRI and toric IOL implantation reported that both were effective in treating mild to moderate grades of astigmatism; with the better outcomes of the use of the toric IOL in higher grades of astigmatism. Evidence proposes a better refractive result is reached by the toric IOL practice. Late literature though would recommend that these outcomes might be further improved by refining the preoperative examinations in combination with the accessibility of updated technologies.

Koch et al [52] were concluded that posterior corneal astigmatism important which can significantly participate in corneal astigmatism overall. It is calculated that $10 \%$ of eyes might have a whole corneal astigmatism calculation errors of more than $0.50 \mathrm{D}$ if the posterior corneal surface is not taken into consideration.

The combination of these values into present IOL formulae and online calculators might raise the precision of postoperative outcomes. Additional investigations will approve these primary results. There is more evidence to propose that the existing IOL estimations might need some extra calculations.

In this study, posterior corneal astigmatism was not incorporated into measurement, as Koch et al [52] concluded that posterior corneal astigmatism is within 0.5 diopters in only $10 \%$ of the cases, which is shown to be of a minor effect on the results. Correspondingly, the new devices that are used for the measurements of the posterior corneal astigmatism are still questionable and not consistent. Another factor is the lack of a solid nomogram to incorporate the posterior corneal astigmatism in both groups. [52]

The construction of perfect capsulorhexis: circular, curvilinear, and with consisting size within $5 \mathrm{~mm}$ diameter to overlays the IOL through $360^{\circ}$ is essential to maximize the stability of IOL, decrease the opportunity of rotation, and decreasing the start of posterior capsular opacification. [53] The late introduction of femtosecond lasers to cataract operations was displayed encouraging outcomes with results of higher accuracy, precision, and safety of the anterior capsulotomy and extra stable and expectable aligning of the IOL.[54,55]

The new introduction of scanning aligning technologies with intra-operative keratometry abilities might finally exceed the current methods, but this will be only obvious with upcoming comparative trials. [56]

The principal criticism of our work design is its nonrandomized non-blinded nature. Randomized clinical trials (RCTs) are the gold typical in interventional studies since they tend to have a balance among the known and unknown confounder variables

The current work is, to our knowledge, the first a largest Egyptian database for the comparison of the astigmatic keratotomy and the toric IOLs in treating corneal astigmatism during phacoemulsification, and the results represent strong evidence that both groups are of high efficacy, predictability, and safety in reducing corneal astigmatism during phacoemulsification with an observed superiority to the toric IOLs. In the current work superiority of the toric IOL was observed in the better UCVA, BCVA, less residual astigmatism, better indices of vector analysis.

\section{Conclusion}

Comparison of astigmatic keratotomy and the toric IOLs in treatment of corneal astigmatism during phacoemulsification showed strong evidence that both groups are of high efficacy, predictability, and safety in reducing corneal astigmatism during phacoemulsification with an observed superiority to the toric IOLs. In this work superiority of the toric IOL was observed in the better UCVA, BCVA, less residual astigmatism, better indices of vector analysis.

\section{Financial support and sponsorship}

Nil.

\section{Conflicts of interest}

There are no conflicts of interest.

\section{References}

1. Hill W. Expected effects of surgical induced astigmatism on Acrysof toric intraocular lens results. J Cataract Refract Surg. 2008; 34(3):364-367.

2. Hoffer KJ. Biometry of 7,500 cataractous eyes. Am J Ophthalmol. 1980 Sep; 90(3):360-8.

3. Hoffmann PC, Hcutz WW. Analysis of biometry and prevalence data for corneal astigmatism in 23239 eyes. J Cataract Refract Surg 2010; 36:1479-1485

4.Ferrer-Blasco T, Montés-Micó R, Peixoto-de-Matos SC, González-Méijome JM, Cerviño A. Prevalence of corneal astigmatism before cataract surgery. $\mathrm{J}$ Cataract Refract Surg. 2009; 35:70-75.

5. Wu E. Femtosecond-assisted astigmatic keratotomy. Int OphthalmolClin 2011; 51(2):77-85

6.Lehmann RP, Houtman DM. Visual performance in cataract patients with low levels of postoperative astigmatism; full correction versus spherical equivalent correction. Clin Ophthalmol. 2012; 6:333-338

7.Chalita MR, Krueger RR, Boxer-Wachler B. Refractive Aspects of Cataract Surgery.

8.Yanoff M, Duker JS, eds. Ophthalmology. 2nd ed. Philadelphia: Mosby Inc; 2004:228-37. 
9. Osher R, et al. Astigmatism Correcting IOLs: Pearls for Your Practice. Ocular Surgery News (suppl). 2009:1-15.

10. Carvalho MJ, Suzuki SH, Freitas LL, et al. Limbal relaxing incisions to correct corneal astigmatism during phacoemulsification. J Refract Surg. 2007 May;23(5):499-504.

11.Bayramlar HH, Dağlioğlu MC, Borazan M. Limbal relaxing incisions for primary mixed astigmatism and mixed astigmatism after cataract surgery. J Cataract Refract Surg. 2003 Apr;29(4):723-8.

12. Kumar NL, Kaiserman I, Shehadeh-Mashor R, Sansanayudh W, Ritenour R, Rootman DS. IntraLase-enabled astigmatic keratotomy for post-keratoplasty astigmatism: on-axis vector analysis. Ophthalmology 2010; 117:1228-1235

13.Bahar I, Levinger E, Kaiserman I, Sansanayudh W, Rootman DS. IntraLase-enabled astigmatic keratotomy for post keratoplasty astigmatism. Am J Ophthalmol 2008; 146:897-904

14-T. Miyake, K. Kamiya, R. Amano, et al.Long-term clinical outcomes of toric intraocular lens implantation in cataract cases with preexisting astigmatism, J Cataract Refract Surg, 40 (2014), pp. 1654-1660

15-N. Visser, N.J. Bauer, R.M. NuijtsToric intraocular lenses: historical overview, patient selection, IOL calculation, surgical techniques, clinical outcomes, and complications, J Cataract Refract Surg, 39 (2013), pp. 624-637

16- G.O. Freitas, J.E. Boteon, M.J. Carvalho, R.M. Pinto Treatment of astigmatism during phacoemulsification, Arq Bras Oftalmol, 77 (2014), pp. 40-46

17- Gale RP, Saldana M, Johnston RL, et al. Benchmark standards for refractive outcomes after NHS cataract surgery. Eye (Lond) 2009;23:1:149-152.

18- Canto AP, Chhadva P, Cabot F, et al. Comparison of IOL power calculation methods and intraoperative wavefront aberrometer in eyes after refractive surgery. J Refract Surg. 2013;29:484-489

19- Hahn U, Krummenauer F, Kölbl B, et al. Determination of valid benchmarks for outcome indicators for cataract surgery: A multicenter, prospective cohort trial. Ophthalmology 2011;118:11:2115-2112.

20- Behndig A, Montan P, Stenevi U, et al. Aiming for emmetropia after cataract surgery: Swedish National Cataract Register study. J Cataract Refract Surg 2012;38:7:1181-1186

21. St Clair RM, Sharma A, Huang D, Yu F, Goldich Y, Rootman D, Yoo S, Cabot F, Jun J, Zhang L, Aldave AJ. Development of a nomogram for femtosecond laser astigmatic keratotomy for astigmatism after keratoplasty. J Cataract Refract Surg. 2016; 42(4): 556-62.

22. Alpins NA, Goggin M. Practical astigmatism analysis for refractive outcomes in cataract and refractive surgery. Surv Ophthalmol 2004; 49:109-22.

23. East Valley Ophthalmology. Surgically Induced Astigmatism Calculator. doctor-hill.com [Cited On: 1stNov, 2016]. Available From: https://sia-calculator.com. [Accessed On 17 June 2017].

24. Visser N Berendschot TT Bauer NJ Jurich J Kersting O Nuijts RM . Accuracy of toric intraocular lens implantation in cataract and refractive surgery. J Cataract Refract Surg. 2011;37:13941402

25. Reinstein DZ, Waring GO III. Graphic reporting of outcomes of refractive surgery. J Refract Surg 2009; 25: 975-8.

26. Reinstein DZ, Archer TJ, Srinivasan S, Kohnen T, Mamalis N, Dupps WJ Jr, Randleman JB. The standard for reporting refractive outcomes of the intraocular lens-based refractive surgery. J Refract Surg 2017; 33(4): 218-22.

27.Matsumoto Y, Hara T, Chiba K, et al. Optimal incision sites to obtain an astigmatism-free cornea after cataract surgery with a $3.2 \mathrm{~mm}$ sutureless incision. J Cataract Refract Surg. 2001;27:1615-1619.
28. Kymionis GD, Kankariya VP, Plaka AD, Reinstein DZ. Femtosecond laser technology in corneal refractive surgery: a review. J Refract Surg. 2012;28:912-920.

29. Abbey A, Ide T, Kymionis GD, Yoo SH. Femtosecond laserassisted astigmatic keratotomy in naturally occurring high astigmatism. Br J Ophthalmol. 2009;93:1566-9.

30.Bauer NJC, de Vries NE, Webers CAB, et al. Astigmatism management in cataract surgery with the AcrySof toric intraocular lens. J Cataract Refract Surg. 2008;34:1483-8.

31. Colin J, Praud D, Touboul D, Schweitzer C. Incidence of glistenings with the latest generation of yellow-tinted hydrophobic acrylic intraocular lenses. J Cataract Refract Surg. 2012;38 (7):1140-6.

32. Bausch \& Lomb Incorporated US FDA Study \#658 - A prospective multicenter study to evaluate the safety and effectiveness of a Bausch + Lomb one-piece hydrophobic acrylic intraocular lens in subjects undergoing cataract extraction. The final clinical study report, dated 2011.

33. Mingo-Botı'n D, Muñoz-Negrete FJ, Won Kim HR, et al. Comparison of toric intraocular lenses and peripheral corneal relaxing incisions to treat astigmatism during cataract surgery. J Cataract Refract Surg. 2010; 36:1700-8.

34. Visser N. Cataract surgery with toric intraocular lens implantation in patients with high corneal astigmatism. J Cataract Refract Surg. 2011; 37:1403-10.

35. Carey PJ, Leccisotti A, McGilligan VE, et al. Assessment of toric intraocular lens alignment by a refractive power/corneal analyzer system and slit-lamp observation. J Cataract Refract Surg. 2010; 36: 222-9.

36. Ruckl T., Dexl A., Bachernegg A., Reischl V. Riha W., Ruckhofer J. Binder P., Grabner G. Femtosecond laser-assisted intrastromal arcuate keratotomy to reduce corneal astigmatism. J Cataract Refract Surg. 2013; 39(4):528-38

37. Roberts T., Sharwood P., Hodge C., Roberts K., Sutton G. Request full-text Request the full-text directly from the authors on ResearchGate. Comparison of Toric Intraocular Lenses and Arcuate Corneal Relaxing Incisions to Correct Moderate to High Astigmatism in Cataract Surgery. Asia-Pacific Journal of Ophthalmology. 2014; 3(1):9-16

38. Thibos LN Wheeler W Horner D. Power vectors: an application of Fourier analysis to the description and statistical analysis of refractive error. Optom Vis Sci. 1997; 74:367-375

39. Roberts T. Management of Coexisting Astigmatism During Cataract Surgery. All content following this page was uploaded. 2016.

40. Matsumoto Y, Hara T, Chiba K, et al. Optimal incision sites to obtain an astigmatism-free cornea after cataract surgery with a $3.2 \mathrm{~mm}$ sutureless incision. J Cataract Refract Surg. 2001;27:1615-1619.

41. Gills JP. Treating astigmatism at the time of cataract surgery. Curr Opin Ophthalmol. 2002;13: 2-6.

42. Navarro R, Palos F, Lanchares E, et al. Lower- and higher-order aberrations predicted by an optomechanical model of arcuate keratotomy for astigmatism. J Cataract Refract Surg. 2009;35: 158-165.

43. Guirao A, Tejedor J, Artal P. Corneal aberrations before and after small-incision cataract surgery. Invest Ophthalmol Vis Sci. 2004; 45: 4312Y4319.

44. Lindstrom RL, Lindquist TD. Surgical correction of postoperative astigmatism. Cornea. 1988; 7:138-148.

45. Wang L, Misra M, Koch DD. Peripheral corneal relaxing incisions combined with cataract surgery. J Cataract Refract Surg. 2003; 29: 712Y722.

46. Holland E, Lane S, Horn JD, et al. The AcrySof toric intraocular lens in subjects with cataracts and corneal astigmatism: a randomized, subject-masked, parallel-group, 1year study. Ophthalmology. 2010;117:2104-11. 
47. Kulkarni A, Mataftsi A, Sharma A, et al. Long-term refractive stability following combined astigmatic keratotomy and phacoemulsification. Int Ophthalmol. 2009; 29:109Y115.

48. Bauer NJC, de Vries NE, Webers CAB, et al. Astigmatism management in cataract surgery with the AcrySof toric intraocular lens. J Cataract Refract Surg. 2008;34:1483-8.

49. Carey PJ, Leccisotti A, McGilligan VE, et al. Assessment of toric intraocular lens alignment by a refractive power/corneal analyzer system and slit-lamp observation. J Cataract Refract Surg. 2010; 36:222-9.

50. AcrySof IQ Toric Directions for Use. Alcon Laboratories, Inc. Fort Worth, TX.

51. Poll JT, Wang L, Koch DD, et al. Correction of astigmatism during cataract surgery: toric intraocular lens compared to peripheral corneal relaxing incisions. J Refract Surg. 2011;27:165-171.
52. Koch DD, Ali SF, Weikert MP, et al. Contribution of posterior corneal astigmatism to total corneal astigmatism. J Cataract Refract Surg. 2012;38:2080Y2087.

53. Ravalico G, Tognetto D, Palomba M, et al. Capsulorhexis size and posterior capsule opacification. J Cataract Refract Surg. 1996;22: 98-103.

54. Kranitz K, Mihaltz K, Sandor GL, et al. Intraocular lens tilt and decentration measured by Scheimpflug camera following manual or femtosecond laser-created continuous circular capsulotomy. J Refract Surg. 2012; 28: 259- 63.

55. Roberts TV, Lawless M, Bali SJ, et al. Surgical outcomes and safety of femtosecond laser cataract surgery: a prospective study of 1500 consecutive cases. Ophthalmology. 2013;120: 227-233.

56. Stuart A, Writer C. High-Tech Toric IOL Axis Alignment. EyeNet Magazine. 2015. 